\title{
Publisher Correction: Control of laser plasma accelerated electrons for light sources
}

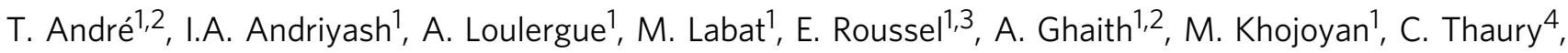

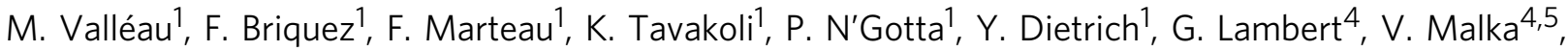

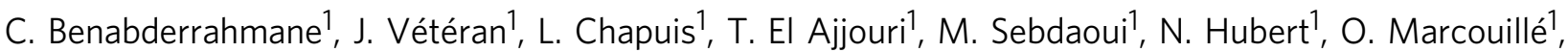 \\ P. Berteaud ${ }^{1}$, N. Leclercq ${ }^{1}$, M. El Ajjouri', P. Rommeluère ${ }^{1}$, F. Bouvet ${ }^{1}$, J.-P. Duval' ${ }^{1}$, C. Kitegi ${ }^{1}$, F. Blache ${ }^{1}$, \\ B. Mahieu ${ }^{4}$, S. Corde (1) ${ }^{4}$, J. Gautier ${ }^{4}$, K. Ta Phuoc ${ }^{4}$, J.P. Goddet ${ }^{4}$, A. Lestrade ${ }^{1}$, C. Herbeaux ${ }^{1}$, C. Évain ${ }^{3}$, C. Szwaj ${ }^{3}$, \\ S. Bielawski ${ }^{3}$, A. Tafzi ${ }^{4}$, P. Rousseau ${ }^{4}$, S. Smartsev ${ }^{4,5}$, F. Polack ${ }^{1}$, D. Dennetière ${ }^{1}$, C. Bourassin-Bouchet ${ }^{1}$, \\ C. De Oliveira ${ }^{1} \&$ M.-E. Couprie (1) $^{1,2}$
}

Correction to: Nature Communications https://doi.org/10.1038/s41467-018-03776-x; published online: 06 April 2018

The original version of this Article contained an error in the last sentence of the first paragraph of the Introduction and incorrectly read 'A proper electron beam control is one of the main challenges towards the Graal of developing a compact alternative of X-ray freeelectron lasers by coupling LWFA gigaelectron-volts per centimetre acceleration gradient with undulators in the amplification regime in equation $11, \mathbf{n x}(\mathbf{n}-\boldsymbol{\beta}) \times \boldsymbol{\beta}: \mathrm{n}$ the two times and beta the two times should be bold since they are vectorsin Eq. 12, $\boldsymbol{\beta}$ should be bold as well.'

The correct version is 'A proper electron beam control is one of the main challenges towards the Graal of developing a compact alternative of X-ray free-electron lasers by coupling LWFA gigaelectron-volts per centimetre acceleration gradient with undulators in the amplification regime.'

This has been corrected in both the PDF and HTML versions of the Article.

Published online: 02 May 2018

Open Access This article is licensed under a Creative Commons Attribution 4.0 International License, which permits use, sharing, adaptation, distribution and reproduction in any medium or format, as long as you give appropriate credit to the original author(s) and the source, provide a link to the Creative Commons license, and indicate if changes were made. The images or other third party material in this article are included in the article's Creative Commons license, unless indicated otherwise in a credit line to the material. If material is not included in the article's Creative Commons license and your intended use is not permitted by statutory regulation or exceeds the permitted use, you will need to obtain permission directly from the copyright holder. To view a copy of this license, visit http://creativecommons.org/licenses/by/4.0/.
}

(c) The Author(s) 2018

\footnotetext{
${ }^{1}$ Synchrotron-SOLEIL, L'Orme des Merisiers, Saint-Aubin 91192, France. ${ }^{2}$ Université Paris-Saclay, Paris 91190, France. ${ }^{3}$ PhLAM, UMR CNRS 8523, Université Lille 1, Sciences et Technologies, 59655 Villeneuve d'Ascq, France. ${ }^{4}$ LOA, École polytechnique, ENSTA ParisTech, CNRS, Université Paris-Saclay, 828 Bd des Maréchaux, 91762 Palaiseau Cedex, France. ${ }^{5}$ Department of Physics of Complex Systems, Weizmann Institute of Science, Rehovot 761001 , Israel. Correspondence and requests for materials should be addressed to M.-E.C. (email: couprie@synchrotron-soleil.fr)
} 